\title{
Sodium hypochlorite in antisepsis of children's and new-born babies' skin prior to insertion of peripheral venous catheter
}

\author{
Paolo Chiari ${ }^{1}$, Domenica Gazineo², Olimpia Pezzullo², Veronica Ricciardi ${ }^{2}$, Lucia Caso², Cristiana \\ Forni $^{3}$ \\ 1. Bologna University, Italy. 2. St. Orsola-Malpighi University Hospital of Bologna, Italy. 3. The Rizzoli Orthopedic Institute \\ of Bologna, Italy.
}

Correspondence: Paolo Chiari. Address: Centro Studi EBN, Azienda Ospedaliero-Universitaria di Bologna, via Albertoni, 15 - 40138 Bologna, Italy. E-mail: paolo.chiari@unibo.it

Received: July 9, 2014

Accepted: August 4, 2014

URL: http://dx.doi.org/10.5430/jha.v3n6p97

DOI : $10.5430 /$ jha.v3n6p97

Online Published: October 14, 2014

\begin{abstract}
Antisepsis of the skin of children to whom a peripheral venous catheter (PVC) is to be attached is an important factor in reducing catheter related infections. No data are available on the effectiveness of sodium hypochlorite. Explorative study of children and new-born babies treated in hospital to ascertain bacterial contamination levels of PVC tips as surrogate infection indicator. In a sample of 51 children and 52 new-born babies, catheter tips were found contaminated for $7.8 \%$ of the children and $3.8 \%$ of the new-born babies. The positive results of this pilot study suggest that serious consideration should be given to assessing Amukine Med 0.05\% for use with PVCs.
\end{abstract}

\section{Key words}

Peripheral venous catheter, Antisepsis of the skin, Children and new-born

\section{I ntroduction}

Catheter related bacteremia is frequent and increases the length of hospital stay, costs, morbidity and mortality of patients affected by it ${ }^{[1]}$. The greatest risk is associated with the use of central venous catheters (CVCs) rather than peripheral venous catheter (PVCs) ${ }^{[2-4]}$. Nevertheless, the enormous number of PVCs used means there is significant incidence of $\mathrm{PVC}$ related complications such as phlebitis, thrombosis and bacteraemia ${ }^{[5,6]}$. The incidence of PVC related bacteremia is only $0.1 \%$, or $0.5 \%$ per 1,000 catheter days, compared with $4.4 \%$, or $2.7 \%$ per 1,000 catheter days, in the case of non tunneled CVCs. If we consider, however, that 25 million catheters are inserted per year in the USA alone, it is clear that septic complications deriving from PVCs represent an epidemiologically significant problem ${ }^{[7]}$.

The role of cutaneous microorganisms in the pathogenesis of these infections means that effective decontamination of the patient's skin is necessary prior to inserting the PVC ${ }^{[4,8]}$.

The most widely used antiseptics include Povidone iodine, isopropyl alcohol and Chlorhexidine, in both aqueous and alcohol solution. The effectiveness of these antiseptics for the reduction of infections has been ascertained with particular 
reference to $\mathrm{CVCs}^{[9,10]}$. However, tests have also been made on $\mathrm{PVCs}^{[8]}$ and they are recommended by the most important Guidelines ${ }^{[2,11,12]}$ with an effectiveness scale which gives top placing to alcohol-based Chlorhexidine.

The hospital in which the present study was made - and many other Italian hospitals - makes substantial use, for antiseptic purposes, of sodium hypochlorite 0.057 gr. with 0.055 gr. of active chloride per $100 \mathrm{ml}$ (Amukine Med 0.05\%). Sodium hypochlorite was the first antiseptic used to prevent infections. Its effectiveness was demonstrated in the 19th century by Ignaz Semmelweis who used it for hand disinfection, thus reducing the incidence and mortality of puerperal fevers ${ }^{[13]}$. Extensive domestic and industrial use has demonstrated the effectiveness and safety of sodium hypochlorite as a disinfectant. The production of electrolytic sodium hypochlorite solution has enabled its wider use as an antiseptic for patients in dialysis, for the irrigation of wounds and burns ${ }^{[14,15]}$ and, in pediatric patients, for antisepsis of the skin around the catheter insertion hole for peritoneal dialysis. In this latter case, the results are similar to those of Chlorhexidine and Povidone iodine, but with substantially lower costs ${ }^{[16]}$. Likewise the Mendoza-Guevara study ${ }^{[17]}$, also on children in peritoneal dialysis, has demonstrated the effectiveness of $1.1 \%$ Amuchina for the prevention of infections from the catheter insertion tip during peritoneal dialysis, without secondary topical reactions.

No studies are available comparing Amukine Med $0.05 \%$ with other recommended antiseptics. Sodium hypochlorite is much cheaper than Chlorhexidine; unlike isopropyl alcohol, it has low volatility and is inflammable. Sodium hypochlorite is not inflammable. Compared with Povidone iodine it is less at risk of deactivation by the blood or by serum proteins and is less toxic for new-born babies ${ }^{[13]}$. Furthermore, sodium hypochlorite has never been associated with cases of contamination from antiseptics. Given the effectiveness of hypochlorite for treatment of the insertion site of catheters for dialysis ${ }^{[18,19]}$, it seems reasonable to hypothesize its use for treating the insertion site of intravascular catheters. However, studies are needed to ascertain its real effectiveness ${ }^{[13]}$.

In view of the low frequency of infections, a direct, randomized comparison would require a very numerous sample. For catheter infections, an acceptable surrogate result could be obtained by ascertaining contamination of the catheter tips $^{[8,10,13,20,21]}$.

The average incidence of PVC tip colonizations is $49.4 \%$ in the case of antisepsis with Povidone iodine, $19.8 \%$ with the use of Chlorhexidine ${ }^{[10]}$. These data contrast, however, with those reported by Lee ${ }^{[22]}$, where removed PVC catheter tips were analyzed for phlebitis and proved not to be contaminated in $98.8 \%$ of cases. Whereas a meta-analysis gave contamination data from $1.6 \%$ to $31 \%$ for Chlorhexidine and from $4 \%$ to $25.4 \%$ for Povidone iodine. However, these data were analyzed with various methodologies and on different typologies of central and peripheral catheters. They do not allow, therefore, precise evaluation of the incidence ${ }^{[23]}$.

Given the difference between these results, which seems attributable to the analytical methodologies used (quantitative vs. semi-quantitative), an evaluation is essential of the basic risk of PVCs inserted with antisepsis made using electrolytic solution of sodium hypochlorite.

\section{Aim}

The aim of the study is to ascertain the contamination frequency of PVC tips inserted in the pediatric population aged 0 to 8 with cutaneous antisepsis using sodium hypochlorite (Amukine Med $0.05 \%$ ) and removed for end of treatment, phlebitis, occlusions or infiltrations.

The result will enable calculation of the sample number necessary in order to carry out future trials comparing the effectiveness of this antiseptic with that of the principal antiseptics recommended by the guidelines ${ }^{[2,11,12]}$. 


\section{Materials and methods}

The observational prospective study was carried out between January and March 2013 in the pediatric wards of the St.Orsola-Malpighi University Hospital of Bologna.

The population included children aged $\leq 8$ and new-born babies from the 36th gestational week. It excluded disoriented patients (for increased risk of self-removal), those for whom consent of both parents could not be obtained and those with sepsis in progress (fever and altered phlogosis indices).

The incidence of PVC tip contaminations was evaluated in cases of removal for end of treatment, phlebitis, occlusions and infiltrations.

A catheter tip was considered "colonized" when it had more than 1,000 colony forming units (CFU) per catheter segment (counting $\geq 1 \mathrm{CFU}$ in a plate spread with $10 \mu \mathrm{l}$ and $\geq 10 \mathrm{CFU}$ in one spread with $100 \mu \mathrm{l}$ ). The culture test was carried out using the Cleri quantitative technique ${ }^{[24]}$. In detail:

- $\quad$ Tryptic Soy Broth added to sterile container containing catheter segment; container shaken with vortex for 30 seconds.

- $\quad 10 \mu \mathrm{l}$ and $100 \mu \mathrm{l}$ of broth, kept in contact with catheter segment, spread on Agar Blood plate (Columbia Agar with $5 \%$ horse blood).

- Incubation of plates in aerobiosis at $35^{\circ} \mathrm{C}$ for 18 hours, extended to 48 hours in the case of negative result.

Catheter related sepsis was considered present in the case of colonization of the catheter tip, a temperature of $>38.5^{\circ} \mathrm{C}$ and its diminution by at least $1^{\circ} \mathrm{C}$ within 48 hours of removal of the catheter itself and without other apparent causes of fever. While catheter related bacteremia was considered present when the same microorganism was observed in both the catheter tip culture and in the haemoculture ${ }^{[10]}$.

The nurses in the wards involved were trained in patient enrolment and in procedures for positioning, removal and sterile collection of PVC tips.

Before inserting a PVC, the nurse performed cutaneous antisepsis of the insertion site with sodium hypochlorite (Amukine Med $0.05 \%$ ), applying it with a tampon and leaving the skin to dry for 60 seconds. The PVC was inserted with non-sterile gloves and no touch technique in accordance with hospital procedures, and fixed to the skin with standard medication. Each day, by means of palpation and interviews with the patient, the research nurse checked for the appearance of phlebitis. Phlebitis was diagnosed using the Infusion Nurses Society evaluation scale ${ }^{[12]}$. When the PVC was no longer necessary, or if complications arose such as phlebitis, occlusions and/or infiltrations, it was removed following sterile collection of the tip, performed by removing the PVC without letting it touch the skin and cutting the last $3 \mathrm{~cm}$ with sterile scissors. The container was sent to microbiology within two hours.

A dedicated form was used for each patient, compiled by appointed personnel from the various operative units.

The data obtained were subsequently registered in a Microsoft Access ${ }^{\circledR}$ electronic database specifically created for these studies. In addition, the results were described according to central trend, frequency and percentage values using SPSS ${ }^{\circledR} \mathrm{v}$. 20 statistical software.

The average incidence of PVC tip colonization was $49.4 \%$ in the case of antisepsis with Povidone iodine, $19.8 \%$ in the case of Chlorhexidine ${ }^{[8]}$. Considering an incidence of $49.4 \%$ and desiring a confidence interval of $95 \%$, not including the confidence interval of $19.8 \%$, the minimum number of cases to be enrolled was 50 children and 50 new-born babies. 
The research protocol was approved by the Ethical Committee of the St.Orsola-Malpighi University Hospital of Bologna.

\section{Results}

\section{Description of samples}

The sample of pediatric patients was gathered over four months (January-May 2013) in the Neonatology, Specialized Pediatrics and Pediatric Surgery, Emergency Pediatrics and Child Neuropsychiatry Wards of the St.Orsola-Malpighi University Hospital of Bologna.

The total sample consisted of 103 patients. Three tips were lost in the case of new-born babies, eight in the case of children.

New-born babies: 52 patients. The PVC remained in position 2.83 days $(3.72 S D)$. The most frequently used place of access was the back of the hand (36.5\%). Antibiotic therapy was infused in $21.2 \%$ of the PVCs. The principal reason for removal was end of treatment (66.7\%). The PVC was applied at the first attempt in $82.4 \%$ of cases.

Children: 51 patients. The PVC remained in position 2.39 days (1.67 SD). The most frequently used place of access was the crook of the elbow (66.7\%). Here, too, the principal reason for removal was end of treatment $(53.8 \%)$, but a high number were removed for leakage (28.8\%). The PVC was applied at the first attempt in $46.2 \%$ of cases, at the second attempt in $34.6 \%$. Antibiotic therapy was infused in $37.3 \%$ of cases.

A detailed description of the variables is given in the table.

Table. Principal features of the sample

\begin{tabular}{|c|c|c|c|}
\hline \multicolumn{2}{|l|}{ Variable } & \multirow{2}{*}{$\begin{array}{l}\text { New-born babies, } \mathbf{N}=\mathbf{5 2} \text {, N. (\%) } \\
18(34.6)\end{array}$} & \multirow{2}{*}{$\begin{array}{l}\text { Children, } \mathbf{N}=\mathbf{5 1} \text {, N. (\%) } \\
28(54.9)\end{array}$} \\
\hline Gender & $\mathrm{M}$ & & \\
\hline Age & Mean $(S D)$ & 7.08 (7.65) days & 1137.24 (1039.06) days \\
\hline Length of application (day) & Mean $(S D)$ & $2.83(3.72)$ & $2.39(1.67)$ \\
\hline \multirow{5}{*}{ Position } & Hand & $19(36.5)$ & $12(36.5)$ \\
\hline & Crook of elbow & $18(34.6)$ & $34(66.7)$ \\
\hline & Forearm & $2(3.8)$ & - \\
\hline & Foot and ankle & $13(25.0)$ & $4(7.8)$ \\
\hline & Wrist & - & $1(2.0)$ \\
\hline \multirow{5}{*}{ Reason for removal } & End of treatment & $28(53.8)$ & $34(66.7)$ \\
\hline & Phlebitis & $2(3.8)$ & - \\
\hline & Dislocation & $7(13.5)$ & $9(17.6)$ \\
\hline & Leakage & $15(28.8)$ & $4(7.8)$ \\
\hline & Occlusion & - & $4(7.8)$ \\
\hline \multirow{5}{*}{ N. attempts } & 1 attempt & $24(46.2)$ & $42(82.4)$ \\
\hline & 2 attempts & $18(34.6)$ & $8(15.7)$ \\
\hline & 3 attempts & $6(11.5)$ & $1(2.0)$ \\
\hline & 4 attempts & $3(5.8)$ & - \\
\hline & 5 attempts & $1(1.9)$ & - \\
\hline \multirow{3}{*}{ Difficulty of access } & Venous fragility & $15(28.8)$ & $9(17.6)$ \\
\hline & Previous attempts & $5(9.6)$ & $2(3.9)$ \\
\hline & Previous phlebitis in same member & $1(1.9)$ & - \\
\hline Antibiotic therapy & & $11(21.2)$ & $19(37.3)$ \\
\hline
\end{tabular}


Of the 103 PVCs, only 6 proved to be colonized, of which 2 (3.8\%, 13.6 as /1,000 days catheters) were in the new-born babies' group and $4(7.8 \%, 32.8$ as $/ 1,000$ days catheters $)$ in the children's group. The microorganisms isolated were Staphylococcus Epidermidis and Staphylococcus Hominis.

In this study only one child, from whom a PVC was removed that proved contaminated, showed hyperpyrexia.

\section{Discussion}

After practicing cutaneous antisepsis using a sodium hypochlorite solution of $0.057 \mathrm{gr}$. with active chloride of $0.055 \mathrm{gr}$. per $100 \mathrm{ml}$. (Amukine Med 0.05\%), the incidence of colonizations in the PVC tips was respectively 3.8\% in new-born babies and $7.8 \%$ in children. The average incidence of colonizations in PVC tips following antisepsis with Povidone iodine is $49.4 \%$, that following antisepsis with Chlorhexidine is $19.8 \%{ }^{[8]}$. The results obtained with Amukine Med $0.05 \%$ therefore reveal lower contamination compared with the other two antiseptics.

In the meta-analysis by Chaiyakunapru ${ }^{[23]}$, the two studies calculating colonization using the quantitative method show $7.1 \%$ and $9.1 \%$ with Chlorhexidine and $16.6 \%$ and $12.4 \%$ with Povidone iodine, but the typology of catheters used is not comparable.

In this study only one child, from whom a PVC was removed that proved contaminated, showed hyperpyrexia, but his body temperature returned to normal body range within 48 hours, a possible indicator of PVC related bacteremia ${ }^{[2]}$.

The principal limit of this study is the small size of the sample, even though it is correctly dimensioned for a pilot study. The lack of comparative studies between antiseptics and sodium hypochlorite necessitated a preventive assessment of the incidence of contaminations in PVC tips. Sodium hypochlorite is fairly cheap, non-irritant, non-toxic and easily handled. Furthermore, there is no evidence as of now that it can be associated with contaminations linked to episodes of epidemics or pseudo-outbreaks ${ }^{[13]}$.

\section{Conclusions}

The positive results of this pilot study suggest that serious consideration should be given to assessing Amukine Med $0.05 \%$ for use with PVCs. Such assessment would require randomized experimental studies comparing Amukine Med $0.05 \%$ with other antiseptics indicated in the guidelines and would also include clinical results.

\section{References}

[1] Pujol M, Hornero A, Saballs M, Argerich MJ, Verdaguer R, Cisnal M, et al. Clinical epidemiology and outcomes of peripheral venous catheter-related bloodstream infections at a university-affiliated hospital. J Hosp Infect. 2007 Sep; 67(1): 22-9. Epub 2007 Aug 27. PMid: 17719678. http://dx.doi.org/10.1016/j.jhin.2007.06.017

[2] O'Grady NP, Alexander M, Dellinger EP, Gerberding JL, Heard SO, Maki DG, et al. Guidelines for the prevention of intravascular catheter-related infections. Centers for Disease Control and Prevention. MMWR Recomm Rep. 2002 Aug 9; 51(RR-10): 1-29. PMid: 12233868.

[3] Vonberg RP, Behnke M, Geffers C, Sohr D, Ruden H, Dettenkofer M, et al. Device-associated infection rates for non-intensive care unit patients. Infect Control Hosp Epidemiol. 2006 Apr; 27(4): 357-61. Epub 2006 Mar 17. PMid: 16622812. http://dx.doi.org/10.1086/503339

[4] O'Grady NP, Alexander M, Burns LA, Dellinger EP, Garland J, Heard SO, et al. Healthcare Infection Control Practices Advisory Committee (HICPAC). Guidelines for the prevention of intravascular catheter-related infections. Clin Infect Dis. 2011 May; 52(9): e162-93. Epub 2011 Apr 1. http://dx.doi.org/10.1093/cid/cir257

[5] Tagalakis V, Kahn SR, Libman M, Blostein M. The epidemiology of peripheral vein infusion thrombophlebitis: a critical review. Am J Med. 2002 Aug 1; 113(2): 146-51. http://dx.doi.org/10.1016/S0002-9343(02)01163-4 
[6] Vandenbos F, Basar A, Tempesta S, Fournier JP, Bertrand F, Vanesland L, et al. Relevance and complications of intravenous infusion at the emergency unit at Nice university hospital. J Infect. 2003 Apr; 46(3): 173-6. PMid: 12643866. http://dx.doi.org/10.1053/jinf.2002.1101

[7] Maki DG, Kluger DM, Crnich CJ. The risk of bloodstream infection in adults with different intravascular devices: a systematic review of 200 published prospective studies. Mayo Clin Proc. 2006 Sep; 81(9): 1159-71. PMid: 16970212. http://dx.doi.org/10.4065/81.9.1159

[8] Small H, Adams D, Casey AL, Crosby CT, Lambert PA, Elliott T. Efficacy of adding 2\% (w/v) chlorhexidine gluconate to 70\% $(\mathrm{v} / \mathrm{v})$ isopropyl alcohol for skin disinfection prior to peripheral venous cannulation. Infect Control Hosp Epidemiol. 2008 Oct; 29(10): 963-5. http://dx.doi.org/10.1086/590664

[9] Maki DG, Ringer M. Risk factors for infusion-related phlebitis with small peripheral venous catheters. A randomized controlled trial. Ann Intern Med. 1991 May 15; 114(10): 845-54. PMid: 2014945. http://dx.doi.org/10.7326/0003-4819-114-10-845

[10] Vallés J, Fernández I, Alcaraz D, Chacón E, Cazorla A, Canals M, et al. Prospective randomized trial of 3 antiseptic solutions for prevention of catheter colonization in an intensive care unit for adult patients. Infect Control Hosp Epidemiol. 2008 Sep; 29(9): 847-53. http://dx.doi.org/10.1086/590259

[11] Royal College of Nursing. Standards for infusion therapy. Royal College of Nursing. London. 2005 Nov.

[12] Infusion Nurses Society. Infusion Nursing Standards of Practice. J Infus Nurs. 2006 Jan-Feb; 29(1 Suppl): S1-92. PMid: 16429002.

[13] Alvarez JA, Macias JH, Macias AE, Rodríguez E, Muñoz JM, Mosqueda JL. Ponce de Leon S. Povidone-iodine against sodium hypochlorite as skin antiseptics in volunteers. Am J Infect Control. 2010 Dec; 38(10): 822-5. http://dx.doi.org/10.1016/j.ajic.2010.05.019

[14] Bruch MK. Toxicity and safety of topical sodium hypochlorite. Contrib Nephrol. 2007; 154: 24-38. PMid: 17099299.

[15] Cruz DN, Ocampo C, Brendolan A, Menara G, Corradi V, De Cal M, et al. Effectiveness of sodium hypochlorite in the prevention of catheter related infections. Contrib Nephrol. 2007; 154: 97-102. PMid: 17099304.

[16] Grosman MD, Mosquera VM, Hernandez MG, Agostini S, Adragna M, Sojo ET. 3\% Amuchina is as effective as the 50\% concentration in the prevention of exit-site infection in children on chronic peritoneal dialysis. Adv Perit Dial. 2005; 21: 148-50. PMid: 16686307.

[17] Mendoza-Guevara L, Castro-Vazquez F, Aguilar-Kitsu A, Morales-Nava A, Rodriguez-Leyva F, Sanchez-Barbosa JL. Amuchina $10 \%$ solution, safe antiseptic for preventing infections of exit-site of Tenckhoff catheters, in the pediatric population of a dialysis program. Adv Perit Dial. 2005; 21: 148-150.

[18] Astle CM, Jensen L. A trial of ExSept for hemodialysis central venous catheters. Nephrol Nurs J. 2005 ; 4: $517-524$.

[19] Wadhwa NK, Reddy GH. Exit-site care in peritoneal dialysis. Contrib Nephrol. 2007; 154: 117-24. PMid: 17099306.

[20] Soifer NE, Borzak S, Edlin BR, Weinstein RA. Prevention of peripheral venous catheter complications with an intravenous therapy team: a randomized controlled trial. Arch Intern Med. 1998 Mar 9; 158(5): 473-7. PMid: 9508225. http://dx.doi.org/10.1001/archinte.158.5.473

[21] Mermel LA, Farr BM, Sherertz RJ, Raad II, O'Grady N, Harris JS, et al. Infectious Diseases Society of America, American College of Critical Care Medicine, Society for Healthcare Epidemiology of America. Guidelines for the management of intravascular catheter-related infections. J Intraven Nurs. 2001 May-Jun; 24(3): 180-205. PMid: 11530364.

[22] Lee WL, Chen HL, Tsai TY, Lai IC, Chang WC, Huang CH, et al. Risk factors for peripheral intravenous catheter infection in hospitalized patients: a prospective study of 3165 patients. Am J Infect Control. 2009 Oct; 37(8): 683-6. Epub 2009 Jun 25. http://dx.doi.org/10.1016/j.ajic.2009.02.009

[23] Chaiyakunapruk N, Veenstra DL, Lipsky BA, Saint S. Chlorhexidine compared with povidone-iodine solution for vascular catheter-site care: a meta-analysis. Ann Intern Med. 2002 Jun 4; 136(11): 792-801. PMid: 12044127. http://dx.doi.org/10.7326/0003-4819-136-11-200206040-00007

[24] Donelli G, Francolini I, Di Carlo V, Di Rosa R, Mastrilli F, Antonelli M, et al. Protocol for prevention, diagnosis and therapy of central venous catheter-associated infections. Istituto Superiore di Sanità. 2002; iii: 33. Rapporti ISTISAN 02/34 (in Italian). 